\title{
MEMÓRIA E RESISTÊNCIA ENTRELAÇADAS: CRAZY BRAVE, DE JOY HARJO'
}

\section{MEMORY AND RESISTANCE INTERTWINED: JOY HARJO'S CRAZY BRAVE}

\section{Liane Schneider ${ }^{2}$}

\begin{abstract}
RESUMO: Proponho discutir neste trabalho a interseccionalidade e o pensamento feminista, principalmente, a partir da forma como essa relação se dá no campo da literatura indígena escrita por mulheres na América do Norte, destacando o local a partir do qual esses textos são atravessados pelo gênero, raça, classe e cosmovisões diversas. A partir das discussões feministas, especialmente o feminismo negro e indígena, tendo em mente as provocações de bell hooks, Audre Lorde, Kimberlé Crenshaw, Lélia Gonzáles, Carla Akotirene, Joyce Green, entre tantas outras, aponto de que forma essa consciência quanto a um antiessencialismo radical pode desestabilizar posições no que diz respeito às mulheres e seus lugares sociais, inclusive dentro do feminismo e principalmente no texto literário Crazy Brave, de Joy Harjo.

Palavras-chave: Literatura indígena. Joy Harjo. Interseccionalidade. Feminismo. Autobiografia
\end{abstract}

ABSTRACT: My objective along this article is to discuss intersectionality and feminist thought, especially from the viewpoint of native women writers in North America, stressing the way such texts in English are crossed by diverse gender, race, class, world perspectives. Departing from feminist and gender discussions, mainly those proposed by black and native voices, having as a theoretical support bell hooks, Kimberlé Crenshaw, Lélia Gonzáles, Carla Akotirene, among others, my idea is to point out, in the literary text studied, that is, Crazy Brave, by Joy Harjo, how a radical antiessentialism helps destabilizing positions in respect to women, women writers and their social roles, even from feminist perspectives.

Keywords: Native literature; Joy Harjo; Intersectionality; Feminism; Memoir

\footnotetext{
${ }^{1}$ Artigo recebido em 15 de agosto de 2019 e aceito para publicação em 22 de novembro de 2019.

2 Professora Titular da UFPB, Departamento de Letras Estrangeiras Modernas e Pesquisadora do CNPQ. Membro do GT da Anpoll A Mulher na Literatura. Email: schliane@gmail.com. ORCID: https://orcid.org/0000-0002-5476-2065
} 


\section{Introduçầo: Joy Harjo, escrita e memórias}

Proponho aqui a discussão dos feminismos e da interseccionalidade no campo da literatura indígena escrita por mulheres na América do Norte, destacando o local social e identitário a partir do qual esses textos são construídos e atravessados pelo gênero, raça, classe e cosmovisões diversas. Tomo como ponto de partida o reconhecimento do caminho questionador percorrido pelos feminismos, especialmente o feminismo negro e indígena, sendo o primeiro protagonista nessa empreitada crítico-teórica, já que vozes como as de Sojourner Truth, e, mais tarde, bell hooks, Audre Lorde, Kimberlé Crenshaw, bem como Lélia Gonzáles, Djamila Ribeiro, Carla Akotirene, Joyce Green, entre tantas outras, apontam na direção de um antiessencialismo radical dentro do amplo espectro do debate feminista, desestabilizando posições no que diz respeito às mulheres e seus lugares sociais, inclusive dentro do feminismo.

Enfocarei nesse trabalho o livro Crazy Brave (2012), de Joy Harjo da Nação Muscogee Creek, definido pela própria autora como um livro de memórias, ou seja, inserido no campo das autobiografias. Assim, meu objetivo também será discutir como essas culturas dos primeiros povos americanos, afetados direta e profundamente pela experiência da colonização, iluminam o debate de gênero e suas intersecções na atualidade através de um olhar retrospectivo e revisionista, destacando principalmente como a interseccionalidade aparece no texto da autora enfocada.

Joy Harjo sempre se percebeu como poeta, musicista e escritora, afirmando jamais ter feito qualquer movimento consciente para escrever como indígena, mas destacando que, desde sempre, a cultura Creek marcou a forma como pensa, escreve, canta e compõe.

Recentemente Joy Harjo, de 68 anos, que já publicou oito livros de poesia, um de memórias, e dois infanto-juvenis, foi indicada para a posição de Poeta Laureada da Biblioteca do Congresso dos Estados Unidos, a primeira indígena a assumir essa posição, segundo notícia divulgada pelo New York Times ${ }^{3}$ no dia 19 de junho deste ano. Ao longo da entrevista que concedeu ao jornal, Harjo se disse ainda em estado de choque, percebendo que esse tipo de premiação honra o lugar ocupado pelos povos indígenas em geral, e a poesia indígena, em particular.

${ }^{3}$ https://www.nytimes.com/2019/06/19/books/joy-harjo-poet-laureate.html, acesso em 14 de julho de 2019 
Além de diversas questões que me atraíram para Crazy Brave nesse momento, o fato de o mesmo iniciar com um agradecimento aos professores, num sentido amplo e não apenas institucional, foi fundamental - na dedicatória, Harjo (2012, p.8) oferece o livro “aos guerreiros do coração, meus professores no Leste, Norte, Oeste e Sul, acima e abaixo" ${ }^{4}$. Os mestres vivos e mortos, próximos ou distantes, a guiam pelo seu relato de vida. O livro Crazy Brave se organiza por essas quatro direções, uma Rosa dos Ventos que se espalha pela obra, cada direção significando uma forma de aprendizagem.

\section{Crazy Brave: um memoir pelo enfoque nativo}

A primeira seção de suas memórias intitula-se East, Leste, a estação primeira que Harjo (2012, p. 15) caracteriza como a direção dos começos, do sol nascente, porta para o conhecimento e florescimento. Além disso, o Leste também apontaria para Oklahoma, local onde a autora nasceu e sua história começou a ser escrita. Percebemos logo que as seções Leste e Norte são as mais longas, onde Harjo busca compreender momentos da infância e juventude e as coletividades em que esteve inserida. O Oeste e Sul são seções mais curtas, talvez pelo pouco distanciamento temporal, já que tratam dos anos de sua entrada na maturidade. O livro não é facilmente classificável quanto ao gênero literário, mesmo dizendo-se um memoir desde a capa, porém justapondo poesia e contos a inúmeras referências à dança, som e movimento, sendo, portanto, híbrido. De toda a forma, para além da reconstrução das memórias de sua vida, Harjo participa, como indígena, mulher e cidadã, da revisão de um período, a segunda metade do século XX no contexto estadunidense.

Uma das primeiras memórias apresentada na seção Leste é de uma viagem de carro, onde se misturam cheiros e ritmos - da loção pósbarba do pai, a voz afinada da mãe, o som que identifica como jazz tocando no rádio do carro, um Cadillac que seu pai comprara com o dinheiro que recebeu pela venda de petróleo em territórios indígenas. E ela resume: "meu rito de passagem para o mundo das humanidades ocorreu, portanto,

\footnotetext{
${ }^{4}$ To the warriors of the heart. To my teachers in the East, North, Weste, and South, above and below. 
através do jazz" (HARJO, 2012, p.18)5 . Percebemos que toda essa "cena" é como que imaginada, já que quem narra talvez nem esteve presente, mas permite pressupor como as coisas teriam ocorrido ou como tudo the foi contado - o namoro dos pais, suas aventuras até que a família se formasse. Possivelmente isso nem seja uma pressuposição, mas um desejo inventado. $E$, na verdade, há uma foto, que ela dispõe ao final do livro que ilustra essa fase da infância, onde Harjo aparece ainda pequena em frente à casa em que moraram, com um cão e um carro ao fundo. Percebemos que o carro não é um Cadillac, que ela sempre ligava ao pai, indicando as fotos de seu memoir com potencial para tanto confirmar como problematizar o conteúdo relembrado/sonhado. De toda forma, os registros fotográficos estão provavelmente aqui atrelados ao que Eurídice Figueiredo (2013, p.22) aponta em seu livro Mulheres ao Espelho, referindo-se a Barthes e seu livro Roland Barthes por Roland Barthes, afirmando que "os destaques autobiográficos seriam as fotografias presentes" naquele livro do autor. As fotos aqui também aparecem comprovando e/ou desafiando o teor das memórias em Crazy Brave.

Thomas Couser (2012), em seu livro Memoir: an introduction, concorda que livros desse gênero são geralmente apresentados como factuais, mas apoiam-se na memória, e devemos ter em mente que essa notoriamente não é confiável, tendo uma capacidade altamente seletiva, podendo ser impressionista e subjetiva, ao invés de factual. Adentramos o livro de Harjo com essa consciência, percebendo fotos e direções que nos localizam no tempo e espaço, poemas e estórias escritas em épocas diversas como pistas para a leitura que a autora propõe; certamente Harjo sinaliza a experiência das mulheres, especialmente as nativas, como ela, vidas entrecortadas por culturas diversas ao longo da experiência estadunidense pós-colonização.

Assim, logo de início, Harjo (2012, p.25) afirma que "não haveria como traduzir essa jornada e o que encontrou ao longo dela até que descobrisse a poesia"6. Reconhece o momento histórico difícil em que nasceu e declara (2012, p. 28): “Nasci de um povo valente e precisávamos de guerreiros. Meu pai e eu havíamos perdido a direção. Eu nasci frágil,

${ }^{5}$ My rite of passage into the world of humanity occurred then, through jazz. Todas traduções do inglês são da autora do artigo.

${ }^{6}$ I had no way to translate the journey and what I would find there until I found poetry. 
fêmea e indígena em terras que foram roubadas"7. Ao mesmo tempo em que ela afirma ter nascido desse jeito, diferente do ideal sonhado, masculino e forte, confirma ter lutado muito para nascer, enfrentando um parto difícil. Atrelado a isso, menciona uma dificuldade com transições: sair de dentro do corpo materno para fora, as passagens do dia para a noite, do aqui para o acolá, do deserto para a água, terra e céu, começos e fins. Mais adiante, problematiza essa definição excessivamente restrita do conceito de guerreiros citada acima e se pergunta: "Quem seriam os guerreiros contemporâneos? O que dizer das esposas, mães e filhas, cujos atos cotidianos de sacrifício e bravura passam geralmente sem reconhecimento e recompensa? Esses atos foram tão cruciais para a segurança e bem-estar dos povos quanto todos outros". (HARJO, 2012, p.150) ${ }^{8}$

Lembra-se de ter adoecido gravemente, com suspeita de pólio, aos quatro anos de idade. Depois de dias de internação, os médicos afirmaram que não havia sido pólio, apesar de todos os sintomas característicos. Durante aqueles dias no hospital, Harjo lembra ter sonhado o tempo todo com crocodilos e acredita que esses a salvaram, já que, na esfera onírica, ela submergia com tais animais, passando a viver sob a água. Como mulher adulta conclui: "Creio que tive uma pólio inicial. Os crocodilos a levaram embora. É possível. Esse mundo é misterioso" (HARJO, 2012, p.39) ${ }^{9}$. Portanto, tais visões não Ihe eram estranhas, sendo que afirma ter frequentemente se sentido "mais acordada na minha vida de sonhos do que na realidade corpórea" (Idem, p.46) ${ }^{10}$. Apenas quando começou a frequentar a escola evangélica é que foi obrigada a internalizar que visões, especialmente em moças e mulheres, eram prejudiciais, ligadas ao demoníaco.

Nessas primeiras socializações, Harjo lembra das normas de comportamento impostas, que, aos poucos, penetravam seu mundo antes mais livre. Recorda de uma tarde em que brincava com meninos - todos tinham cinco anos, ninguém vestia blusa. Até que a mãe grita por ela - que

\footnotetext{
${ }^{7}$ I am born of brave people and we were in need of warriors. My father and I had lost the way. I was born puny and female and Indian in lands that were stolen.

8 What of contemporary warriors? And what of the wives, mothers, and daughters whose small daily acts of sacrifice and bravery were usually unrecognized or unrewarded? These acts were just as crucial to the safety and well-being of the people.

${ }^{9}$ I believe now that I had the beginnings of polio. The alligators took it away. It is possible. This world is mysterious.

${ }^{10}$ I often felt more awake in my dreaming life than I did in this corporeal reality. 
viesse colocar uma camiseta. Por que não chamava seu irmão? Questiona Harjo. A mãe responde - "ele é menino"! Joy responde - "mas nós somos iguais"!11 Nesse dia a mãe ameaça surrá-la e ela lembra: "Entrei e vesti uma camiseta. Sabia que não podia retrucar. Naquele pequeno instante a alegria de ter cinco anos - de ser um corpo e suas respirações - acabou"12. (Harjo, 2012, p.47) Diz ter visto tudo num relance, as vergonhas do que está "lá embaixo", as cabeças baixas e as portas fechadas da casa e da igreja, tudo num piscar de olhos. Mas afirma que, apesar de ter feito o solicitado, vestindo a roupa para esconder suas diferenças invisíveis, decidiu ali mesmo que só "concordaria temporariamente com aquilo, que com ela não seria assim. Encontraria seu jeito"!13 (Idem p.47). Regras de comportamento sempre excessivamente binárias marcaram sua criação e instintivamente Harjo percebe que haveria sofrimentos em seu caminho.

Nas últimas páginas da seção Leste, a autora considera que a literatura a salvou da tristeza de várias crises, como a do casamento dos pais. Lia sem parar Bishop, Blake, Dickinson e Lewis Carroll na biblioteca da escola antes dos dez anos e gostava daquilo, sem nem saber por quê. No mesmo período, lembra dos surtos de raiva do pai, que ela adorava e temia, escondendo-se sob a mesa durante esses episódios, ele ficando ainda mais furioso por ela não ser suficientemente valente, brave, enfim. A falta de bravura era o pior dos desaforos que podia receber à época.

A Seção seguinte, intitulada North/Norte, já inicia com um tom mais grave. Harjo anuncia que o Norte é o lugar onde vivem os professores difíceis. É a direção dos ventos frios, sendo essa quase uma profecia sobre o período em que tem de lidar com o divórcio dos pais. Após a separação desses, relembra os vários pretendentes que apareceram para cortejar sua bela mãe. No final das contas, ela acabou aceitando um homem jovem e branco, que parecia simpático, até vir morar com eles; a nova casa alugada pela mãe e padrasto foi um marco de pesadelos e violências. A mãe parou de cantar, o padrasto só permitia que saísse para trabalhar. Surrou com uma cinta a irmã mais jovem, à época com 5 anos e, quando a mãe não reagiu como esperava, Harjo entendeu que a vida, como conhecia até então,

11 "He is a boy" (...) "But we look the same"

12 I went inside to put on a shirt. I knew better than to talk back. In that small moment the earthly delight of being five years old, of being utterly body and breath, came falling down.

${ }^{13}$ I decided that, though temporarily I had to acquiesce, I would have nothing to do with it. I would find my way. 
acabara. Tudo era sufocante: a vigilância constante, as regras da divisão do trabalho inflexíveis e marcadas por gênero, como aponta:

A casa agora estava calada com nosso esforço por manter as coisas em ordem. Minha irmã e eu tínhamos um monte de obrigações, por sermos meninas. Eu me encarregava da limpeza, da lavagem das roupas, de passar a ferro para toda a família e cuidar dos mais novos. Nossos irmãos só tiravam o lixo e cortavam a grama. Tentei brigar por um rodízio de tarefas, pois não sentia haver justiça em tal distribuição, mas não havia negociação (HARJO, p.60$61)^{14}$.

Há que se considerar que Harjo, nascida nos anos quarenta, viveu um contexto ainda não profundamente marcado pelos desdobramentos feministas posteriores e, mesmo nas culturas nativas, os arranjos sociais vinham sofrendo modificações há séculos quanto a vários aspectos, consequência da presença de uma força colonizadora externa, branca e patriarcal.

Joyce Green (2007), estudiosa canadense do feminismo indígena, aponta que, independentemente das especificidades do feminismo aborígine, esse construiu desde o início uma crítica ao colonialismo, especialmente no que se referia às relações raciais e de gênero, tanto nas comunidades não-indígenas como indígenas, já que esse sistema organizador do poder estava em toda a parte. Já Verna St Denis (2007) destaca que historicamente sempre foi pouco provável que as indígenas dessem prioridade às desigualdades de gênero apenas, sem levar em conta questões políticas e econômicas de interesse dos povos aborígenes. A autora confessa ter imediatamente se sentido atraída pela proposta das feministas de cor no sentido de provocar o feminismo mainstream quanto às múltiplas formas de discriminação e desigualdade, tais como o racismo, o sexismo e o heterosexismo. De fato, o pensamento feminista interseccional, que Akotirene considera como "uma ferramenta ancestral" (2018, p.20) passou a dar visibilidade maior à matriz de diversas opressões, que antes apareciam de forma estanque. E a partir da diversidade dos lugares que as

14 Our house now was quiet with our labor to keep it in order. My sister and I had the bulk of duties, because we were female. I was in charge of cleaning, doing laundry, including the ironing for the family, washing dishes, and childcare. Our brothers emptied the trash and mowed the lawn. I tried making a case for rotating duties. I didn't feel it was a fair distribution. There was no negotiating. 
mulheres ocupam, há também uma gama de posições no que se refere a forma de tratar do gênero. Djamila Ribeiro (2018, p.292), em sua entrevista em Explosão feminista, afirma que o feminismo clássico ou dominante "tem limites muito marcados, como não debater a interseccionalidade, as opressões". Diz identificar-se mais com "as feministas da década de 1960 (...) que estavam pensando a interseccionalidade, ou a questão de raça, para além do debate de gênero". Ainda que possamos defender que o feminismo surgiu como um discurso anti opressão, é fato que a questão racial não esteve presente nas primeiras discussões. Algo semelhante ocorre com as mulheres indígenas - quando entram no debate feminista, sempre trazem a questão étnico-racial à pauta, já que "mulher" foi um termo em geral negativamente marcado quando atrelado a elas devido às diferenças que sempre foram ressaltadas nas mesmas.

Voltando a Crazy Brave, após o novo casamento da mãe, as memórias do período são descritas por Harjo $(2012$, p.61) como "um longo silêncio, uma eternidade de céus cinzentos"15, cinza esse que podemos claramente atrelar às normas sexistas e racistas às quais toda a família passa a estar mais fortemente submetida. Esse período cobre o final da escola básica até a adolescência. É também nessa época que começou a sentir olhares do padrasto sobre si e aguarda por uma visão que the indique a forma de deixar aquela casa. A partir de então passa a revoltar-se com a igreja, não querendo mais frequentar missas nem ler a Bíblia, que vinculava aos brancos opressores, os quais forçaram a dominação das mulheres pelos homens. Além disso, não concordava com as proibições de danças e profecias que pregavam na igreja. Planejava fugir, ir viver com hippies na Califórnia. Quando o padrasto passou a tentar apalpá-la enquanto a mãe trabalhava, entendeu que era o momento de sair dali. Descreve o medo que sentia, mas também sua força interna:

Estava apavorada, mas mesmo assim conseguia escutar meu conhecimento, meu saber interno. Esse era meu leme, um flamejar de luz inteligente, infalível no meio dessa vida destrutiva, terrível e bela; uma vertente do divino, uma trilha que conduz aos

${ }^{15}$ (...) a long silence. It is an eternity of gray skies. 
ancestrais e professores que nos amam. (HARJO, 2012, p.81) 16

Ao invés de fugir, de esconder-se, esse saber the dizia que havia outra maneira, outra saída possível. E, assim, Harjo se informa sobre cursos colegiais em Santa Fé, no Novo México, que facilitavam a entrada de estudantes indígenas. Inscreve-se e é aceita. Enquanto se deslocava para lá, pressentiu ter tomado a direção certa. Em Santa Fé, voltou a desenvolver suas sensibilidades artísticas. Também nessa época participa de reuniões de grupos indígenas, formando elos de amizade e formas de resistência:

Éramos os "skins" (pele vermelha), viajando juntos numa época de metamorfose, encarando os mesmos traumas da colonização e desumanização. Éramos evidência direta da luta dos nossos ancestrais, os quais escutávamos, já que falavam através de nós, apesar de que, como outros jovens da nossa geração, usássemos calças boca de sino e óculos do tipo John Lennon. (HARJO, 2012, p.86) ${ }^{17}$

As atividades culturais e artísticas desses grupos, segundo Harjo (2012, p. 87), tinham marcas inegáveis de suas especificidades:

Enquanto produzíamos arte, assistíamos eventos culturais e debatíamos a Família e as heranças tribais, sentíamos que estávamos no início de uma enorme renascença cultural indígena, prontos e à beira de uma explosão de ideias que dariam formato à Arte indígena contemporânea nos anos vindouros. ${ }^{18}$

Mesmo nesse contexto promissor, via as dificuldades a serem enfrentadas pelas mulheres:

As mulheres muito frequentemente internalizam a raiva; na escola indígena, várias de nós nos mutilávamos. Cada cicatriz nossa era evidência de que

\footnotetext{
${ }^{16}$ Though I was blurred with fear, I could still hear and feel the knowing. The knowing was my rudder, a shimmer of intelligent light, unerring in the midst of this destructive, terrible, and beautiful life. It is a strand of the divine, a pathway for the ancestors and teachers who love us. ${ }_{17}$ We were all "skins" travelling together in an age of metamorphosis, facing the same traumas from colonization and dehumanization. We were direct evidence of the struggle of our ancestors. We heard them and they spoke through us, though like others of our generation, we wore bell-bottoms and Lennon eyeglasses.

${ }^{18}$ As we made art, attended cultural events, and struggled with family and tribal legacies, we sensed that we were at the opening of an enormous indigenous cultural renaissance, poised at the edge of an explosion of ideas that would shape contemporary Indian art in the years to come.
} 
queríamos viver. Tínhamos de manter as facas longe de uma das alunas, uma das melhores pintoras do grupo. Outra, tivemos de levar ao hospital para fazer lavagem estomacal. (HARJO, 2012, p.90) ${ }^{19}$

A seção seguinte, West/Oeste, a $3^{\text {a }}$. do livro, se anuncia como um direcionamento para o fechamento de ciclos, sendo também a porta que leva aos ancestrais e aos testes. Representa tanto o deixar como o ser deixado e o aprender a encontrar o caminho na escuridão. Nessa seção, Harjo relembra suas tentativas de relacionar-se mais intimamente, como quando se apaixonou por um colega Cherokee aos 15 anos, em Santa Fé. Com ele e um grupo de alunos, descobriu a força do teatro, visto por ela como uma porta para o mundo dos sonhos. As peças que encenaram foram tão bem avaliadas que acabaram por fazer uma turnê pelo país. Quando essa turnê acabou, alguns foram para faculdade, outros foram tentar a vida em NYC. Harjo se descobriu grávida nesse momento, tendo que retornar à casa do padrasto. O namorado disse que enviaria passagem de ônibus para ela em breve, mas essa nunca chegava. Já estava com quatro meses de gravidez, não conseguindo mais esconder seu estado, quando pega dinheiro emprestado e segue atrás do namorado. Quando o encontra, descobre que já tinha uma filha pequena e que não sabia o que fazer com outro filho a caminho. Durante a gravidez, Harjo adaptou-se a lugares que ele arranjava cá e lá, na casa de amigos ou com a sogra. No dia do parto, lembra de ter ido a pé com o pai da criança até o hospital indígena, pois não tinha carro nem dinheiro para um táxi. O companheiro a deixou no hospital e foi trabalhar. Sentiu-se imensamente só, sem a mãe por perto e com uma sogra que sabia estar fazendo trabalhos de magia para livrar-se dela. Harjo relembra que, quando tentou agachar-se na hora exata de parir, Ihe foi dito pelos enfermeiros que se continuasse agindo daquela forma seria amarrada. Sozinha e com dor, pensava. "É natural sentar-se ou agachar-se para parir. Deitar-se força o corpo a um trabalho muito mais difícil, contrário ao enorme fluxo de músculos e ao impulso de vida"20 (p. 123). Na verdade,

\footnotetext{
${ }^{19}$ Women often turn their anger inward, and at Indian school some of us mutilated ourselves. Each scar was evidence that we wanted to live. We had to keep knives away from one student. She was one of the best painting students. We carried another student to the Indian hospital to have her stomach pumped.

${ }^{20}$ It is natural do sit or squat to give birth. Lying down forces the body to work harder, against the tremendous flow of muscle and the urge to live.
} 
considera que nada era natural naquele hospital, enquanto mira seu bebê pela primeira vez:

Nós nos olhamos naquele deslumbrante momento de juramento sagrado (...). Eu olhei para ele com um amor insuportável e me perguntava: 'Em que fui me meter? Como vamos dar conta'? Nunca havia me sentido tão vulnerável. (...) Quando finalmente peguei meu bebê no colo, a enfermeira montou guarda ao meu lado, como se eu fosse machucá-lo. Eu era jovem e indígena e, portanto, ignorante (HARJO, 2012, p. $124)^{21}$.

Considera que essa desconfiança generalizada quanto às suas capacidades estava afinada com a proposta que lhe fora feita ao adentrar o hospital, quando tentaram convencê-la de que esse seria o momento perfeito para uma esterilização, isso aos dezesseis anos de idade. Não assinou o documento, mas perguntou-se quantas mulheres nativas provavelmente teriam concordado sem entender exatamente o teor do texto. Relembra que o período pós-parto foi horrível. A sogra sempre tentando prejudicá-la por achar que havia estragado a vida do filho. A vida ficando sem graça, previsível: acordar, comer pizza fria, dar banho nas duas crianças: a filha do companheiro e seu bebê.

Em seguida, adentramos a última seção do livro, o Sul/South, apresentada como a direção do alívio, para onde os pássaros migram após o inverno, onde há flores, fogo e criatividade. Há também, como bem coloca Harjo, o rabo de duas cobras entrelaçadas formando uma espiral em círculos repetidos, em transformação eterna. Nesse "Sul", Harjo reconhece que o cotidiano não seria suficiente para sustentar a urgência por expressão artística que sentia e conclui:

Acredito que se você não responder ao sons e urgências dos seus talentos, eles darão as costas a você. Ou irão arrastá-la para baixo, para uma imensa tristeza por terem sido abandonados. Era como se tivesse abandonado em Santa Fé meus sonhos de ser uma artista. Meu marido tinha a mesma sensação e,

\footnotetext{
${ }^{21}$ My son and I stare at each other in the stunning moment of that sacred vow. (...). I looked at him with an unberable love, and with troubling questions: what have I gotten myself into? How will we ever make it through? I have never felt so vulnerable. (...) When I finally got to hold my boy, the nurse stood guard as if I would hurt him. I was young and Indian and therefore ignorant.
} 
assim, empacotamos tudo e voltamos para lá (HARJO, 2012, p. 135-136) 22 .

Lá, em Santa Fé, Harjo consegue emprego, mas tem de pagar a metade do que ganha para a babá. Certo dia descobre uma carta de amor do marido para essa jovem. Só então sentiu-se capaz de abandoná-lo. Finalmente consegue entrar na Universidade do Novo México, com o apoio de vários grupos indígenas que a auxiliam nos primeiros tempos por lá. A partir desse lugar e momento, reconhece que havia uma revolução se organizando por todo o país. Um período de tomada de consciência, inspirada no movimento pelos direitos civis. Confessa que ela e seus amigos indígenas estavam em ebulição "com a possibilidade de conseguir paz e justiça para todos os povos nativos". (HARJO, 2012, p. 138) e pondera:

Embora os negros Americanos tenham nos inspirado, com os povos indígenas era diferente. A maioria de nós não desejava se tornar plenamente americano. Queríamos manter a integridade das nossas culturas tribais e afirmar nossas nações tribais individuais. Desejávamos ser guerreiros, artistas e sonhadores tradicionais e contemporâneos do século vinte. (HARJO, 2012, p. 139) $)^{23}$

Percebe também as nuances de gênero dessa batalha:

Havia uma revolução quanto ao poder feminino emergindo. Para as mulheres indígenas, essa revolução ficava submetida às lutas tribais, embora soubéssemos que havia lutas particulares das mulheres. Sentia que o coração do país estava se quebrando em pedaços. (HARJO, 2012, p.139) ${ }^{24}$

À época, Harjo lembra que não queria se envolver emocionalmente, já que recém enfrentara uma separação. Acaba, porém, conhecendo um líder indígena nos movimentos políticos. Reparou nos

\footnotetext{
22 I believe if you do not answer the noise and urgency of your gifts, they will turn on you. Or drag you down with their immense sadness at being abandoned. I felt like I had left my dreams of being an artist in Santa Fé. My husband felt the same, so we packed up the children and returned.

23 Though black America inspired us, Indian peoples were different. Most of us did not want to become full-fledged Americans. We wished to maintain the integrity of our tribal cultures and assert our individual tribal nations. We inspired to be traditional-contemporary twentiethcentury warriors, artists, and dreamers.

24 There was a revolution of female power emerging. It was subsumed for native women under our tribal struggle, though we certainly had struggles particular to women. I felt the country's heart breaking.
} 
longos cílios dele, sentiu seu perfume e fugiu, enquanto ele dizia - "ainda vou pegar você"! De fato, na manhã seguinte ele já conseguira seu telefone e ligou recitando poemas que, como diz Harjo, abriram seu coração novamente.

Juntos começamos a alimentar uma linguagem em comum. Eu comecei a entender que a poesia não precisava necessariamente ser da Inglaterra ou usar um inglês que sempre se mostrasse saudoso em relação à Europa. (...). Nos poemas dele estavam seu pueblo, sua gente, nosso amor e o amor pela justiça. A língua inglesa parecia satisfeita ao ocupar essas novas formas. (HARJO, 2012, p.141) ${ }^{25}$

Relata que tempos depois, já tendo mais uma filha com esse poeta, num dia comum, teve seu primeiro ataque de pânico. Telefona para casa e avisa ao companheiro que não consegue continuar a caminhar sozinha. Ele não entende, diz que venha, que estão esperando por ela. Se arrasta até lá e, depois disso, enfrenta várias crises do tipo. Em um dia específico, Harjo se dá conta que apenas a poesia poderia causar alguma abertura em seu coração. A partir daí começa a escrever poemas com mais intensidade, buscando uma cura para si.

Infelizmente o novo companheiro começou a beber em exagero e Harjo entra em estado de alerta. Uma vidente a avisou que estava em perigo, que a violência a rondava. Na próxima bebedeira dele e na primeira nova agressão, chama a polícia, que o leva preso por uns dias. Assim, termina esse romance e ela transforma a casa em que vivia numa espécie de abrigo para mulheres indígenas. Harjo (2012, p. 158) observa que:

Não havia casas ou abrigos para vítimas de abuso doméstico, especialmente para mulheres indígenas. Não se esperava que nós falássemos sobre dificuldades pessoais quando nossos povos estavam se dedicando à causa. Deveríamos deixar de lado nossos problemas domésticos para o bem das nações indígenas, dedicando energia para nossos lares e na busca por justiça. ${ }^{26}$

\footnotetext{
${ }^{25}$ Together we nurtured a common language. I began to understand that poetry did not have to be from England of an English that was always lonesome for its homeland in Europe. In his poems were his pueblo and his people, our love and the love for justice. The English language was pleased to occupy new forms.

${ }^{26}$ There were no safe houses or domestic abuse shelters then, especially for native women. We weren't supposed to be talking about personal difficulties when our peoples were laying down
} 


\section{Breves consideraçồes}

Há que se ter em mente que, nas várias Américas, as agendas feministas nunca foram fácil ou pacificamente aceitas, em quaisquer grupos sociais, étnicos, culturais em que essas surgiam. Verna St Denis (2007) afirma que, entre as indígenas canadenses, houve inicialmente uma desconfiança generalizada de tais agendas mainstream, pois, participar do debate sobre direitos das mulheres, dava destaque ao sistema patriarcal eurocêntrico, ainda que como crítica; porém, várias delas viam-se de toda a forma dentro e fora desse sistema, ocupando, na verdade, um entre lugar, de onde avaliavam e avaliam seus impactos individual e coletivamente.

Vale mencionar que, a partir do Brasil, Marize Vieira de Oliveira (2018, p.302) publicou um capítulo do livro Explosão feminista, de Buarque de Holanda, dando voz a diversas mulheres indígenas, entre as quais, Sonia Guajajara, discutindo questões semelhantes, e podemos ler abaixo o que Guajajara coloca:

Existe um feminismo indígena, mas do nosso jeito. [...] Talvez esse termo não seja o mais adequado para a nossa realidade. $\mathrm{O}$ feminismo soa radical, longe da gente. Mas temos sim buscado protagonismo dentro das aldeias e para fora, nas nossas lutas, procurando visibilidade. [...] Para a gente, esse é o nosso feminismo: se empoderar e assumir o protagonismo.

O que se percebe nas memórias de Harjo é também uma busca por protagonismoo que busquei respeitar ao longo desse artigo, priorizando sua voz. Ao final de mais um casamento e com um segundo filho para criar, Harjo acaba se dando conta de que tinha outras escolhas a fazer. Passa a publicar seus poemas em revistas universitárias, apesar das eventuais crises de pânico. Procura razões para isso através de seus sonhos, os quais coloca em poemas. Harjo diz ter percebido que antes, até dominava o inglês, utilizando frases convencionais, tipo 'me passa o sal' ou 'encontro vocês lá'. Mas afirma ter recebido um convite da própria poesia para algo diferente, sendo que seguiu por essa estrada. Assim, seu memoir existe porque a poesia existe. Como em tantas outras culturas e visões de mundo, a arte, o

their lives for the cause. We were to put aside all of our domestic problems for the good of our tribal nations and devote our energies to our homes and to justice. 
prazer estético, seja esse definido pela crítica como maiúsculo ou minúsculo, atrela-se a um impulso por sobrevivência e resistência, que, repetido e repetido, pode nos levar em direção ao Sul, onde o rabo entrelaçado de duas cobras em espiral, dando laçadas em uma eterna transformação ${ }^{27}$, como indica Harjo, quem sabe consiga nos reerguer e transformar, inventando novos espaços de bravura em tempos pouco promissores.

\section{Referências}

AKOTIRENE, C. O que é interseccionalidade? Belo Horizonte: Letramento, 2018

COUSER, G. T. Memoir: an introduction. New York: Oxford UP, 2012.

FIGUEIREDO, E. Mulheres ao Espelho: autobiografia, ficção, autoficção. Rio de Janeiro: Ed UERJ, 2013.

GREEN, J. Taking account of aboriginal feminism. In: Green, Joyce (Org.), Making space for indigenous feminism. Black Point: Fernwood Publishing/Zed books, 2007, p.20-32.

HARJO, J. Crazy brave: a memoir. New York: WW Norton \& Company, Inc., 2012.

OLIVEIRA, M. V. de S. Feminismo indígena. In: HOLANDA, H. B. de (Org.) Explosão feminista: arte, cultura, política e universidade. São Paulo: Companhia das Letras, 2018, p.301-316.

LEÓN, C. de. Joy Harjo is named Poet Laureate. The New York Times. https://www.nytimes.com/2019/06/19/books/joy-harjo-poet-laureate.html, acesso em 14 de julho de 2019.

RIBEIRO, D. Entrevista. In: HOLANDA, H. B. de (Org.) Explosão feminista: arte, cultura, política e universidade. São Paulo: Companhia das Letras, 2018, p.261-299.

ST DENIS, V. Feminism is for everybody: aboriginal women, feminism and diversity IN: Green, Joyce (Org.), Making space for indigenous feminism. Black Point: Fernwood Publishing/Zed books, 2007, p.33-51.

${ }^{27}(\ldots)$ the tails of two snakes making a spiral, looping over and over, an eternal transformation. 